\title{
Modeling and Finite Element Analysis of Leaf Spring Using Pro-Engineer and ANSYS Softwares
}

\author{
Salem Elsheltat ${ }^{1 *}$, Abdulbaset Alshara ${ }^{2}$, Walid Elshara ${ }^{3}$ \\ ${ }^{1}$ Department of Mechanical Engineering, College of Engineering, Misurata University, Libya \\ 2,3 Department of Medical \& Electromechanical Engineering, College of Medical Technology- \\ Misurata, National Board for Technical and Vocational Education, Libya
}

DOI: https://doi.org/10.21467/proceedings.4.30

* Corresponding author email: salem.sheltat@eng.misuratau.edu.ly

\begin{abstract}
Leaf spring is an important mechanism of suspension system in vehicles that is still widely used. In automotive industry, the motivation is to increase the capability to produce vehicles of inordinate quality at best prices. For saving the natural resources, reducing the weight of vehicle is constantly the priority of car manufacturing. While decreasing the weight of an automobile, engineering designers should consider the strength of materials and the size of components. This deigned leaf spring is built up of several plates with steel material, but the steel leaf spring has an excessive weight. The weight of leaf spring may perhaps be reduced by using strength materials, and reducing the thickness of leafs. The purpose of this paper is to study the deformations and stresses of the current design of leaf spring under static and dynamic loading conditions. The system of this leaf spring is designed to minimize the vibration forces that a vehicle confronts when moving on a surface. This leaf spring has been sketched via ProEngineer software, and analyzed through ANSYS. As a result of the conducted stress study, the deformations due to the static and dynamic loading are determined along the leaf spring. The main point of the analysis study is to improve the quality of this design for a leaf spring with a longer life, and achieve a big reduction in vibration forces; for the cost reduction, modification is carried out by varying the thickness of spring leaves; and an optimization study is accompanied to satisfy the allowable values of deformation and the factor of safety by changing the size of meshing elements. Altogether analytically calculated values of deformations and stresses are someway comparable to the values obtained from ANSYS.
\end{abstract}

Keywords: Leaf spring, Modeling, FEA, Deformation, Safety factor.

\section{Introduction}

When an engineering designer desires stiffness, negligible deflection is an adequate approach, as long as it does not destruct function. Elasticity is often required and is regularly provided by solid bodies with specific geometries. These bodies can give flexibility to the degree the designer strives for. This flexibility varies linearly or nonlinearly with applied loads. For the significance of machinery to engineering designers, springs have been comprehensively

(C) 2018 Copyright held by the author(s). Published by AIJR Publisher in Proceedings of First Conference for Engineering

Sciences and Technology (CEST-2018), September 25-27, 2018, vol. 2.
This is an open access article under Creative Commons Attribution-NonCommercial 4.0 International (CC BY-NC 4.0)

A iR license, which permits any non-commercial use, distribution, adaptation, and reproduction in any medium, as long as the original work is properly cited. ISBN: 978-81-936820-6-7 
Modeling and Finite Element Analysis of Leaf Spring Using Pro-Engineer and ANSYS Softwares

investigated. Furthermore, there are world-wide rapid developments of mass-production techniques for making low cost ingenious springs .Mostly, springs are assorted as flat springs, wire springs, or special designed springs. Flat springs are compartmentalized into cantilever and elliptical shapes [1]. Leaf springs are widely used for the suspension system in cars and commercial vehicles to absorb vibrations and shocks. The spring is made of multi leaves with different lengths. The spring leaf is designed of an arc-shape. The inner leaf is the tallest blade and bent from both ends to form two holes where the spring should be attached to the frame of the vehicle. The outer blades are shorter than the inner blades, and those blades are all held up using bolts and rebound clips. The spring is attached from its centre to the axle of the vehicle. Importantly, the spring should be fixed from the front eye of the master blade to the vehicle's frame and freely in vertical motion from the rear [2]. For simplicity of the calculations, the bending stresses and deformations in laminated leaf springs are determined from formatted standard equations for simply supported beams. The main components (master leaf, graduated leaf, eye, camber, span, central clamp, rebound clips) of a semi-elliptic leaf spring are shown in figure 1.

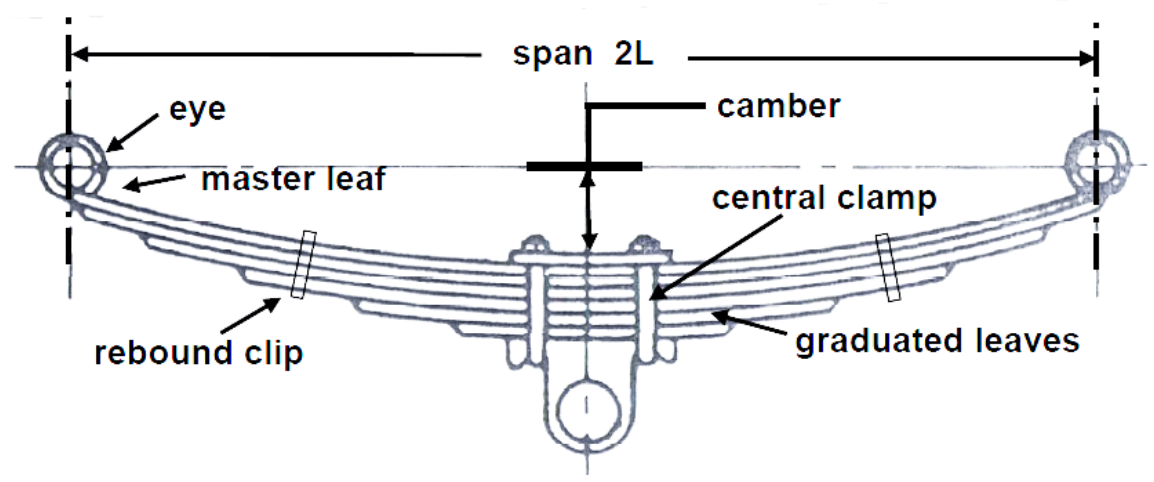

Figure 13 Semi-elliptic leaf spring [2].

\subsection{Literature Survey}

Some of the pervious studying papers that have done an excellent contribution are mentioned in this paragraph. Sarika Yede and Sheikh [3] modelled and finite element analysed a leaf spring made of different materials. The study concluded that from the comparison of different materials that glass fibre is better than composite material and EN-45 Steel. Amitkumar Magdum [4] analysed leaf springs using finite element methods considering the dynamic effect on stability of vehicle. The work concluded that the best harmonic response of a spring depends on the different materials and loads. The capacity to absorb energy is more in composite materials and less in steels. Shiva Shankar and Vijayarangan [5] designed and fabricated a composite mono leaf spring and tested it under loading conditions, and compared it to the steel spring. They concluded that more stresses are occurred in the steel spring than they are in the composite spring when subjected to the same loading condition. Also, they found out that the natural frequency is higher in the composite spring. Mahesh Khot and Sameer Shaikh [6] carried out a FEA analysis and did an experimental study on a leaf spring 
made of a composite material and found out that this material can offer advantages in strength, light weight relative to conventional metallic materials. Trivedi Achyut and Bhoraniya [7] performed static and dynamic analysis on leaf Springs, the research concluded that with respect to conventional steel leaf spring composites having high strength to weight ration. Also, composites have less weight than conventional steel leaf spring. G Harinath Gowd and E Venugopal Goud [8] modelled a leaf spring and carried out a static analysis using ANSYS software and they concluded that the maximum stress is developed at the inner side of the eye sections. They recommended that the selected material must have good ductility, resilience and toughness to avoid sudden fracture for providing safety and comfort to the occupants. S. Karditsas, and others [9] have shown design process using finite element method (FEM) and simulation and tested a parabolic 2-leaf-spring for front axles of heavy duty under operating conditions. The stress limitations were exceeded and approximately uniform stress distribution was achieved along the length of the two leaves.

\subsection{Problem Statement}

This deigned leaf spring is built up of several plates with steel material, but the steel leaf spring has an excessive weight. The weight of leaf spring may perhaps be reduced by using strength materials, and reducing the leaf thickness. Another worry, due to the concentration of stresses at the sudden change of cross sections of the spring geometry, failure might occur at the eyes of the spring and at the portions around the central hole of the spring. Hence, stress analysis study is needed to be carried out on the entire geometry of the leaf spring.

\subsection{Objectives of This Work}

Firstly, a mathematical model will be developed for studying the deformations and stresses of the current design of leaf spring under loading conditions. Secondly, this leaf spring will be sketched via Pro-Engineer software, and analysed through ANSYS. The main point of the stress investigation is to improve the quality of this design for a leaf spring with a longer life, and achieve a big reduction in vibration forces. Thirdly, for the cost reduction, modifications will be carried out by varying the thickness of spring leaves. Fourthly, an optimization study will be accompanied to satisfy the allowable values of deformation and factor of safety by changing the size of meshing elements. Lastly, the results will be verified by comparison of the solution of analytical analysis and FEA.

\section{Materials and Methods}

The most common material that has been used widely in the world for the leaf spring industry is conventional steel. The advantages of using Steel are local availability, low cost, high strength. The selected material for the designed laminated leaf spring has mechanical properties such as Young's modulus of $200 \mathrm{GPa}$, tensile strength of $880 \mathrm{MPa}$, yield strength of $600 \mathrm{MPa}$, Fatigue of $275 \mathrm{MPa}$, and Poisson's ratio of 0.3 [10].

Proceedings of First Conference for Engineering Sciences and Technology (CEST-2018), vol. 2 
Modeling and Finite Element Analysis of Leaf Spring Using Pro-Engineer and ANSYS Softwares

\subsection{CAD Modelling via Pro/Engineer}

Pro/E is a suite of programs that are used in the design, analysis, and manufacturing of a virtually unlimited range of products. Its field of application is generally mechanical engineering design, although recent additions to the program are targets at ship building and structural steel framework as well [11]. In this current paper, a computer model creation using the powerful design tool (Pro/Engineer) is to be carried out for a laminated leaf spring. The geometry of the spring has dimensions of (number of spring leaf $(n=4)$, Length of span of the spring $(2 \mathrm{~L}=1000 \mathrm{~mm})$, thickness of leaf $(\mathrm{t}=10 \mathrm{~mm})$, width of leaf $(\mathrm{b}=220 \mathrm{~mm}))$. Assuming that the total load of $140 \mathrm{KN}$ is applied on the spring, and the material assigned to the leaf spring has an allowable deflection of $(49.72 \mathrm{~mm})$. Figure 2 shows the 3D solid model of the leaf spring that sketched via Pro/Engineer, this model is to be exported for a simulation via ANSYS software.

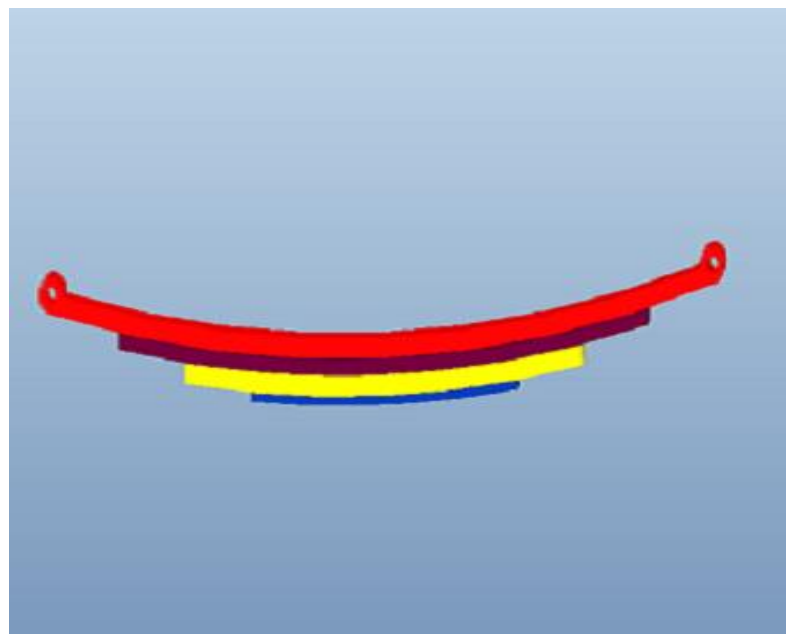

Figure 2: Pro-E model of the designed leaf spring

\subsection{Finite Element Analysis via ANSYS}

Finite element method (FEM) is a numerical method for solving differential equations that describe many engineering problems. One of the reasons for FEM's popularity is that the method results in computer programs versatile in nature that can solve many practical problems with a small amount of training .Capitalizing on an engineer knowledge of mechanics, reinforcing an engineer knowledge, and solving problems that can only be tackled numerically on the computer, using software tools like ANSYS, Pro/E, SolidWorks [12]. The goal of numerical simulation is to make predictions concerning the response of physical systems to various kinds of excitation and, based on those predictions, make informed decisions. To achieve this goal, mathematical models are defined and corresponding numerical solutions are computed. The main elements of numerical simulation and associated errors are summarized among these five stages: physical reality, mathematical model, numerical solutions, predictions and decision [13]. 


\subsection{Simulation Steps in ANSYS}

All real-life structures are three-dimensional. It is engineers who make the approximation as a one-dimensional (e.g., beam) or a two-dimensional (e.g., plane or plane solid) structure. When the stresses on a plane normal to one of the axes are approximately zero, then the solid is assumed in the state of plane stress. Similarly, when the corresponding strains are zero, the solid is in the state of plane strain [11].

In this current work, the leaf spring can be assumed to be solved as a beam element, using different sizes of elements. A static structure study is to be carried out using ANSYS 15 beginning with assigning the engineering data of the material used in this design, and going through the following steps.

\subsection{Geometry and Boundary Conditions}

When starting a static structure study in ANSYS, geometry has to be defined. The Pro-E model of a leaf spring is imported to ANSYS. The boundary conditions are to be specified. Figure 3 shows the static structure of the spring, where fixed supports are applied at both eyes and load ( $F=7868.3 \mathrm{Ibf})$ is vertically applied as shown in figure 3 .

\subsection{Finite Element Discretization}

We can discretize the geometry of the domain, depending on its shape, into a mesh of more than one type of element (by shape or order). For example, in the approximation of an irregular domain, we can use a combination of rectangles and triangles. However, the element interfaces must be compatible in the sense that solution is continuous [14]. For this case of study, the geometry of the leaf spring can be meshed by creating rectangle meshing type with element size of 0.3 in, 44950 elements, and 221503 nodes. . Figure 4 shows the finite element discretization of the laminated leaf spring.

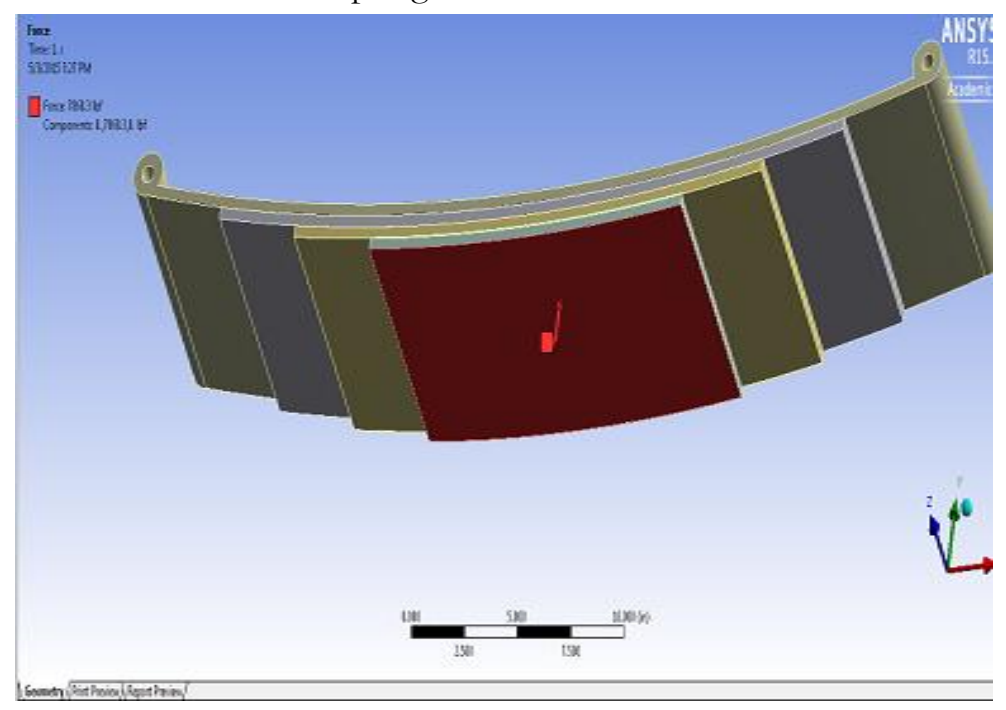

Figure 3: Static structure of laminated leaf spring

Proceedings of First Conference for Engineering Sciences and Technology (CEST-2018), vol. 2 630 


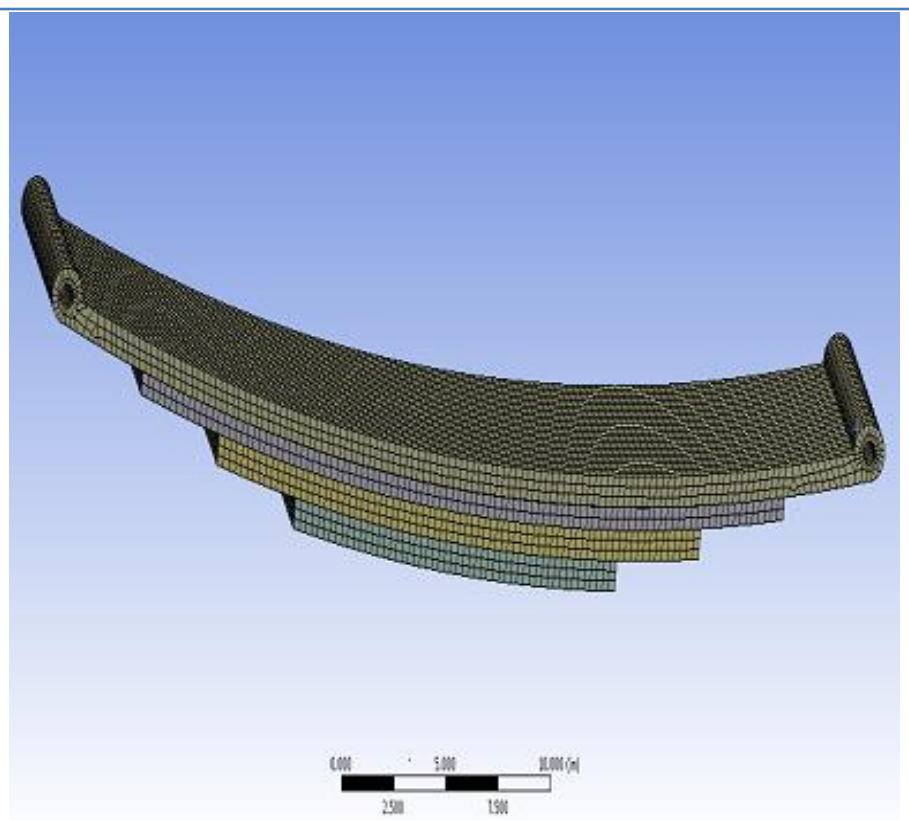

Figure 4: Finite element discretization of the leaf spring

\section{Theory and Calculation}

Laminated leaf spring can be assumed to be a beam of layers, which is fixed from one end and loaded from the other end. Figure 5 shows a simple cantilever type leaf spring. Considering a cantilever beam with the same length of span (2L), width (b), and thickness $(\mathrm{t})$ of the designed leaf spring and subjected to the load $(\mathrm{F})$ [2].

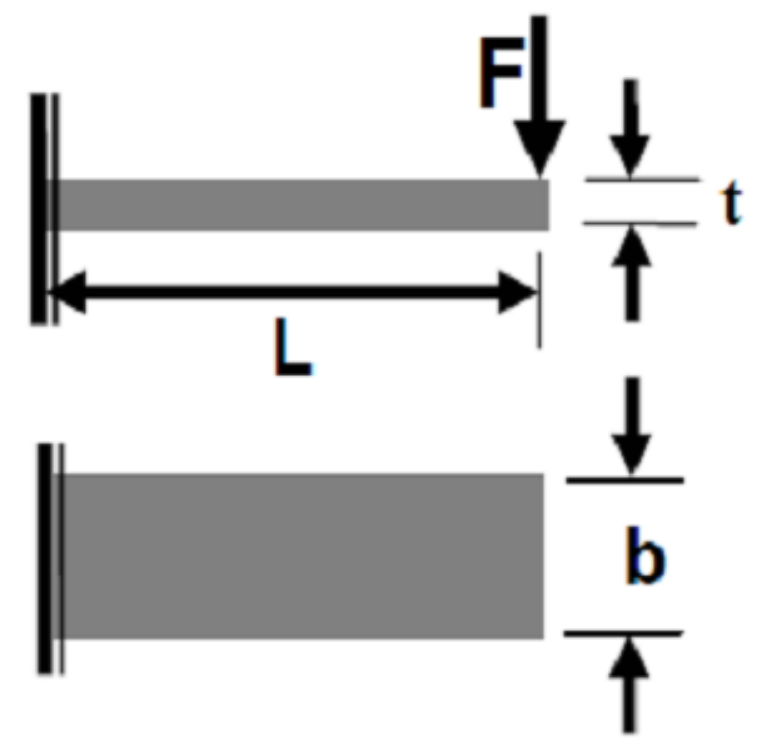

Figure 5: Simple cantilever type leaf spring [2] 


\subsection{Stresses and Deformation Equations}

From the basic equations of bending stress and deflection of beam, the maximum bending stress $\left(\sigma_{\max }\right)$, maximum deflection $\left(\delta_{\max }\right)$, Von Mises stress $\left(\sigma_{v}\right)$, and factor of safety (F.S) can be calculated from the following formulas [1], [2].

$\sigma_{\max }=\frac{6 F L}{n b t^{2}}$

$\delta_{\max }=\frac{4 F L^{3}}{n Y_{a} b t^{3}}$

$\sigma_{v}=\sqrt{\sigma_{\max }^{2}+3 \tau_{\max }^{2}}$

$f . s=\frac{\sigma_{y}}{\sigma_{v}}$

Where: maximum shear stress in the beam $\left(\tau_{\max }=F / A\right), \mathrm{A}$ is the cross section of the beam $\left(\mathrm{A}=\mathrm{b}^{*} \mathrm{t}\right), \sigma_{y}$ is the yield stress, and $\mathrm{Y}_{\mathrm{a}}$ is Young's modulus for the material as previously specified.

\section{Results and Discussion}

From the beam equations that introduced in the previous section, the applied load is varied by an increment of $500 \mathrm{~N}$, the corresponding maximum stresses, Von Misses Stresses and deformations are determined; the maximum load that this current leaf spring can bear without failing based on safety factor is $17500 \mathrm{~N}$. Those equations are coded to the equations window of the Engineering Equation Solver (EES) software, and then solved. Table 1 shows the relations among the applied load $(\mathrm{F})$, the maximum stress $\left(\sigma_{\text {max }}\right)$, Von Mises stress $\left(\sigma_{v}\right)$, maximum deflection $\left(\delta_{\max }\right)$, and factor of safety o (F.S) for the leaf spring.

Table 1: Variation stresses and deformations with load

\begin{tabular}{|c|c|c|c|c|}
\hline $\mathrm{F}(\mathrm{N})$ & $\sigma_{\max }(\mathrm{Pa})$ & $\delta_{\max }(\mathrm{m})$ & $\sigma_{v}(\mathrm{~Pa})$ & \multicolumn{1}{l|}{$\mathrm{F} . \mathrm{S}$} \\
\hline 7000 & $2.386 \mathrm{E}+08$ & 0.01989 & $2.387 \mathrm{E}+08$ & 2.514 \\
\hline 9500 & $3.239 \mathrm{E}+08$ & 0.02699 & $3.239 \mathrm{E}+08$ & 1.852 \\
\hline 10500 & $3.580 \mathrm{E}+08$ & 0.02983 & $3.580 \mathrm{E}+08$ & 1.676 \\
\hline 11500 & $3.920 \mathrm{E}+08$ & 0.03267 & $3.921 \mathrm{E}+08$ & 1.53 \\
\hline 12500 & $4.261 \mathrm{E}+08$ & 0.03551 & $4.262 \mathrm{E}+08$ & 1.408 \\
\hline 13500 & $4.602 \mathrm{E}+08$ & 0.03835 & $4.603 \mathrm{E}+08$ & 1.303 \\
\hline 14500 & $4.943 \mathrm{E}+08$ & 0.04119 & $4.944 \mathrm{E}+08$ & 1.213 \\
\hline 15500 & $5.284 \mathrm{E}+08$ & 0.04403 & $5.285 \mathrm{E}+08$ & 1.135 \\
\hline 16500 & $5.625 \mathrm{E}+08$ & 0.04688 & $5.626 \mathrm{E}+08$ & 1.066 \\
\hline 17500 & $5.966 \mathrm{E}+08$ & 0.04972 & $5.967 \mathrm{E}+08$ & 1.005 \\
\hline
\end{tabular}

Proceedings of First Conference for Engineering Sciences and Technology (CEST-2018), vol. 2 632 
Modeling and Finite Element Analysis of Leaf Spring Using Pro-Engineer and ANSYS Softwares

\subsection{ANSYS Simulation Solution}

Based on the design parameters that have been specified for the leaf spring and from table 1 the critical applied load can be assumed to be $17500 \mathrm{~N}$.

\subsection{Distribution of Stresses, Deformations, and Factor of Safety}

For thickness of $10 \mathrm{~mm}$ with mesh size of 0.3 in, the stresses are calculated using the tool of beam results in ANSYS, all analysis results are illustrated in the following figures. Figure 6, shows the variation of Von Mises stresses caused to the leaf spring, and figure 7 is shown the corresponding total deformation in the leaves of the spring. For verification of this numerical results, firstly the maximum deformation and stress occurred at the areas around the force's applied point, which is the centre of the leaf, secondly the concentration of the stress accumulated at the eyes of the leaf spring.

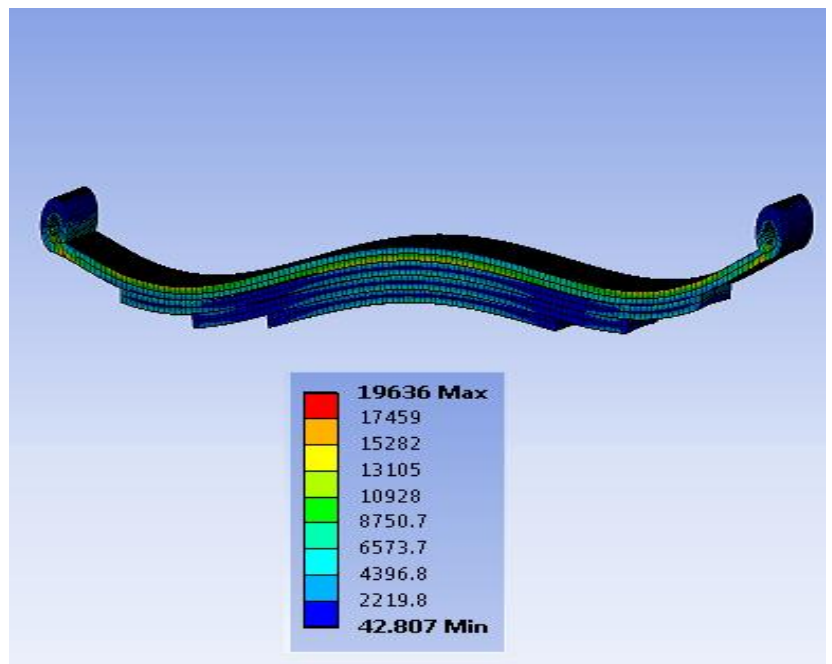

Figure 6: Von-Mises stress distribution (unites in psi)

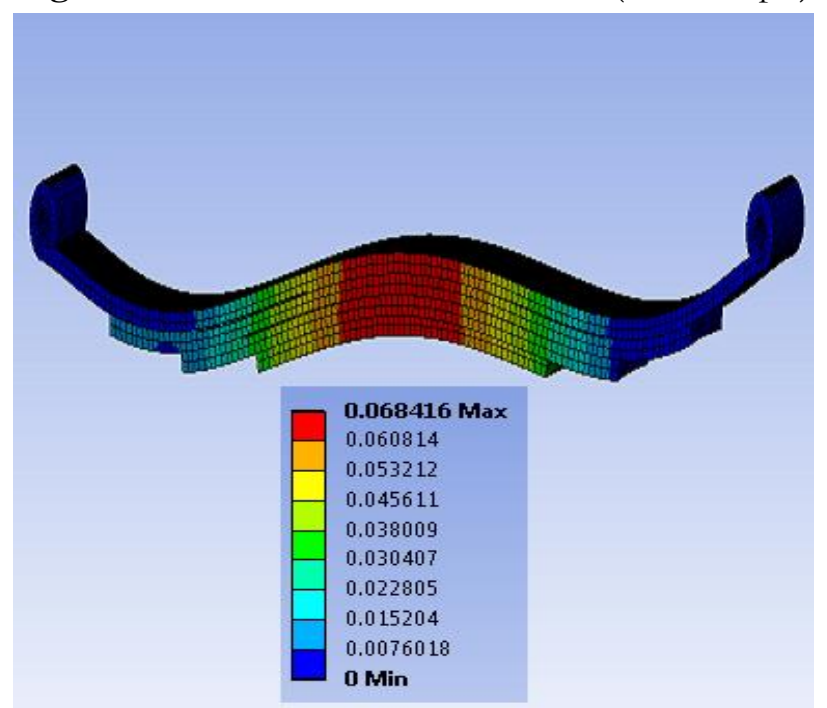

Figure 7: Total deformation distribution (unites in inches) 
The safety factor for each element of this design is plotted in figure 8 , since the safety factor is affected directly by the maximum stress, the minimum factor of safety occurred at the stress concentration areas of the spring. The numerical solution supports the design of the spring proposed in this work with safety factor of 1.8, which is good enough to be used in the car applications, with a convincing life span.

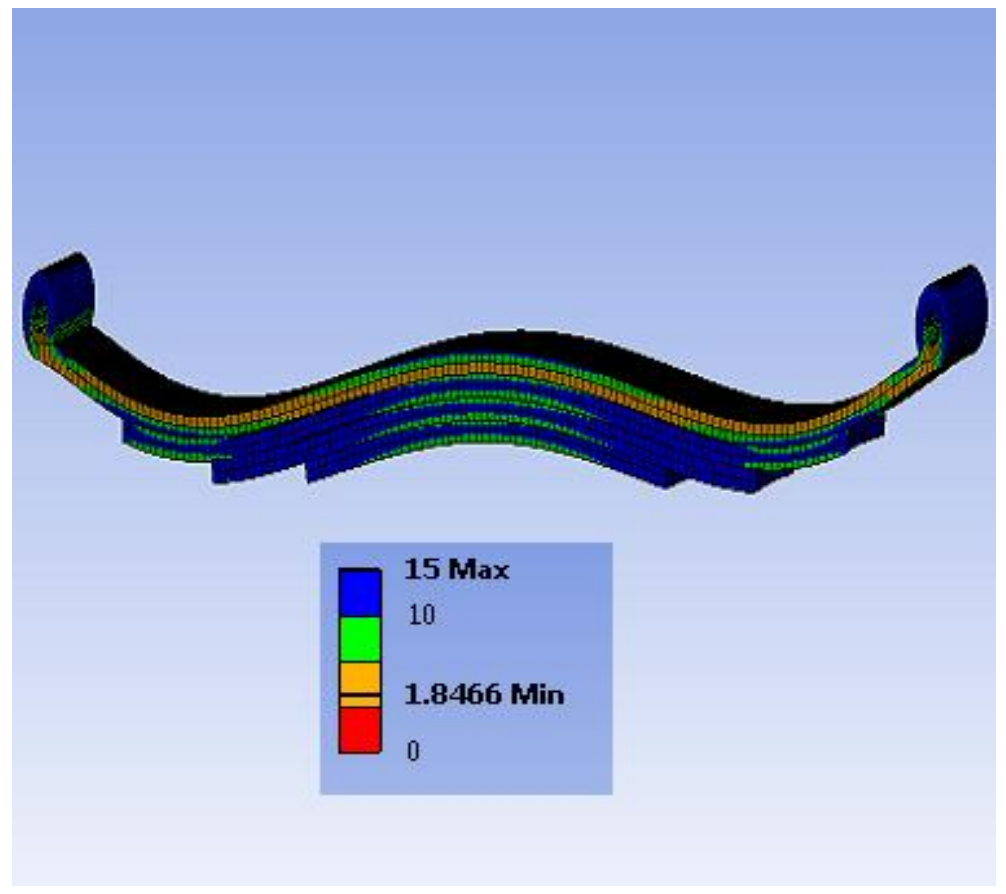

Figure 8: Safety factor distribution for the leaf spring

\subsection{Design Parameter Variation}

The leaf thickness is one of the important design parameter that should be varied in favour of reducing weight. ANSYS has a powerful simulation tool for changing the parameters, and the corresponding solutions can provide such a great visualization that helps the engineers for making their decisions. In this work as it's shown in table 2, stresses, deformations, safety factors are determined for each different value of the leaf thickness. From the table 2, its noticeable that as the thickness is increased, the better safety factor is achieved .However, engineers, should be worried about the weight and cost of the product.

Table 2: Variation thickness with stress, deformations, and Safety factors

\begin{tabular}{|l|l|l|l|l|}
\hline $\begin{array}{l}\text { Thickness } \\
(\mathrm{mm})\end{array}$ & $\begin{array}{l}\text { Mesh Element } \\
\text { size (in) }\end{array}$ & $\begin{array}{l}\text { Von-Mises } \\
\text { Stress (psi) }\end{array}$ & $\begin{array}{l}\text { Deformation } \\
(\mathrm{in})\end{array}$ & $\begin{array}{l}\text { Safety } \\
\text { Factor }\end{array}$ \\
\hline 10 & 0.3 & 19636 & 0.068416 & 1.8466 \\
\hline 15 & 0.3 & 9406 & 0.02281 & 3.8549 \\
\hline 25 & 0.3 & 6876.6 & 0.015006 & 5.2729 \\
\hline
\end{tabular}

Proceedings of First Conference for Engineering Sciences and Technology (CEST-2018), vol. 2 
Modeling and Finite Element Analysis of Leaf Spring Using Pro-Engineer and ANSYS Softwares

\subsection{Convergence Study}

A convergence study is performed by varying the size of mesh element. Increasing the size of meshing element will reduce the number of equations that ANSYS solve. Therefore, the computer with higher specifications is required for less running waiting time. The disadvantage of increasing element meshing size is that it is not possible to create a mesh that precisely covers the entire area for a complicated geometry. This approximated solution will lead to deviations from the exact solutions. At the moment, the version of the simulator used in this work is academic and not able to perform a concise advanced study, but the principle of the converge study is applied by increasing the size of element for meshing the entire geometry of the leaf spring. The stresses and deformations are determined as it's shown in table 3. The mesh size of 0.3 with 44950 elements and 221503 nodes is the optimal meshing size among the options stated in this particular work in table 3.

In future studies, the mesh size should be reduced to its minimum to find the exact solutions, and to obtain a better decision for competitive design. The recommended analysis to complete this convergence study for obtaining more satisfying results is to reduce the element size of meshing by $0.1 \mathrm{in}$. This would increase the number of elements and nodes. In each step, run the solve tool to collect the results, and repeat this step until a no change in results is noticed. Consider the last mesh to be optical for your design and advanced studies. The numbers of elements and nodes might exceed millions, so keep in mind that high computer specifications are needed.

Table 3: Convergence study

\begin{tabular}{|l|l|l|}
\hline Meshing Size (in) & Stress (Psi) & Deformation (in) \\
\hline 0.5 & 16146 & 0.0080364 \\
\hline 1 & 14600 & 0.0079407 \\
\hline 2 & 17108 & 0.0079639 \\
\hline
\end{tabular}

\section{Conclusions}

In leaf spring world industry, reducing weight, and increasing strength are always the main matter in order to yield a competitive product. For that reason, the weight of leaf spring was reduced by using strength steal material, and reducing the thickness of leaves of the desired laminated spring. The geometry of spring was modelled using Pro/E and statically structurally analyzed using ANSYS. The Finite element analysis was the selected method for stress and deformation distributions. The thickness of the spring was varied with stresses and deformations. Based on a convergence study for the accuracy of the results obtained from FEM, the meshing element size is selected to be 0.3 inches for this current condition.

The theoretical results and finite element method solutions are somehow deviated, so an experimental solution is recommended for future studies. Finally, the optimal design steel leaf spring was made up of four plates with thickness of $10 \mathrm{~mm}$, span of $1000 \mathrm{~mm}$, and width of 
$220 \mathrm{~mm}$. The steel material that is used in this spring should have a yield stress of $600 \mathrm{Mpa}$ and subjected to a load less than $17500 \mathrm{~N}$. If heavier loads are desired, we recommend using a composite material that is lighter and has a better stiffness, though the cost reduction should be questioned.

\section{References}

[1] Richard Gordon, Keith Nisbett, "Shigly's Mechanical Engineering Design," The McGraw-Hill Companies, Ninth Edition, ISBN. 978-0-07-352928-8, 2009.

[2] ] R.S. Khurmi, J.K. Gupta,, “A textbook of Machine Design,” Eurasia Publishing, year 2005.

[3] Sarika S. Yede, M. J. Sheikh, "Modeling and Finite Element Analysis of Leaf Spring," International Journal of Computer Applications, Proceedings on ICQUEST, no. 2, pp. 24-26, IJCA.2014,. Access online on 02 April 2018 at https://www.ijcaonline.org/proceedings/icquest/number2/18697-1548

[4] Amitkumar Magdum, "Dynamic Analysis of Leaf Spring Using ANSYS," International Journal of modern Trends in Engineering and Research, vol. 3, Issue. 10, pp. 51-59, IJMTER.. October, 2016. Access online on 10 April 2018 at https://www.ijmter.com/past-issues/

[5] G.S .Shiva Shankar, Sambagam Vijayarangan, "Mono Composite Leaf Spring for Light Weight Vehicle - Design, End Joint Analysis and Testing," Materials Science (MEDŽIAGOTYRA), vol.12, No.3, pp. 220-225, MSM.. 2006. Received 20 June 2005; accepted 07 April 2006.

[6] Mahesh A. Khot, Sameer M. Shaikh, "Finite Element Analysis and Experimental Study of Composite Leaf Spring," International Journal of Innovations in Engineering Research and Technology, vol.3, Issue.1, pp. 01-09, IJIERT. January, 2016. Access online on 15 April 2018 at http://www.ijiert.org/vol iss.php?id=17

[7] Trivedi Achyut V, R.M. Bhoraniya, "Static and Dynamic Analysis of Automobile Leaf Spring (TATA ACE)," International Journal of Science Technology \& Engineering, vol.1, Issue.11, pp. 151-156, IJSTE. May, 2015. Access online on 10 May 2018 at http://ijste.org/index.php?p=Archieve\&v=1\&i=11.

[8] G Harinath Gowd, E Venugopal Goud, "Static Analysis of Leaf Spring," International Journal of Engineering Science and Technology, vol.4, No.8, pp. 3794-3803, IJEST. August, 2012.

[9] S. Karditsas, G. Savaidis, A. Mihailidis, "Leaf springs - Design, calculation and testing requirements," 35th International Conference on Mechanics and Materials, At Faliraki, Greece, pp. 117-126, ICMMFG. June, 2014.

[10] SushilB.Chopade, Prof.K.M.Narkar, Pratik K Satav, "Design and Analysis of E-Glass/Epoxy Composite Monoleaf Spring for Light Vehicle," International Journal of Innovative Research in Science Engineering and Technology, vol..4, Issue.1, pp. 18801-18808, IJIRSET. January, 2015.

[11] Roger Toogood, "Pro/Engineer Wildfire 3.0 Tutorial and Multimedia CD," SDC Publications Schroff Development Corporation, ISBN.978-1-58503-307-2, 2006.

[12] Nam-Ho Kim, Bhavani V.Sankar, "Introduction to Finite Element Analysis and Design," John Wiley and Sons,Inc, ISBN.978-0-470-12539-7, 2009.

[13] Barna Szabo, Ivo Babuska, "Introduction to Finite Element Analysis Formulations, Verification and Validation , "John Wiley and Sons,Inc ,First Edition, ISBN.978-0-470-97728-6, 2011.

[14] J.N.Reddy, "An Introduction to the Finite Element Method Formulations, Verification and Validation, " The McGrawHill Companies, Third Edition, ISBN.13-978-0-07-060741-5. 